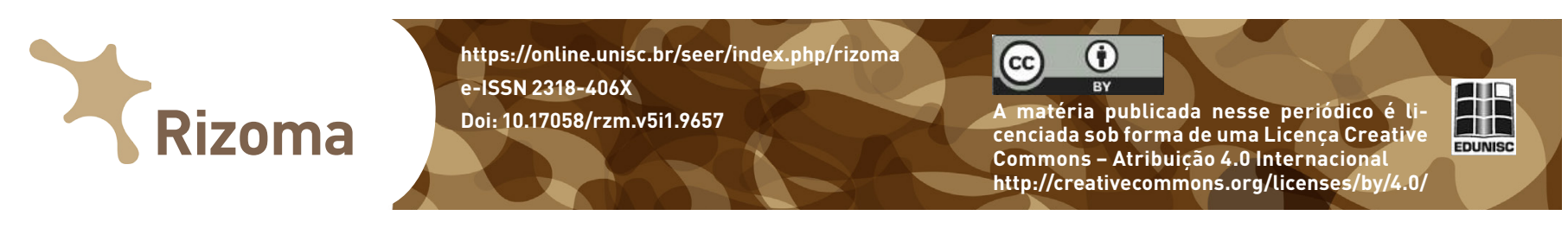

\title{
Entrevista
}

\section{Entrevista a Diniz Gonçalves Júnior}

Resumo: Esta entrevista com o poeta Diniz Gonçalves Júnior é uma das que compõem a série de entrevistas que vem sendo realizada com autores brasileiros de literatura e poesia digitais. Esta série de entrevistas faz parte de um projeto de mapeamento da literatura digital brasileira e surge inspirada na vasta pesquisa desenvolvida sobre o tema pelo Professor Jorge Luiz Antonio, desde o começo dos anos 2000. A intenção deste projeto é dar continuidade a esta pesquisa, expandi-la e aprofundá-la.

Palavras-chave: literatura digital brasileira; poesia digital; mapeamento; releituras digitais.

Esta entrevista com o poeta Diniz Gonçalves Júnior é uma das que compõem a série de entrevistas que vem sendo realizada com autores brasileiros de literatura e poesia digitais. Esta série de entrevistas faz parte de um projeto de mapeamento da literatura digital brasileira, e surge inspirada na vasta pesquisa desenvolvida sobre o tema pelo Professor Jorge Luiz Antonio, desde o começo dos anos 2000. A intenção deste projeto é dar continuidade a esta pesquisa, expandi-la e aprofundá-la.

Tanto o projeto como as entrevistas possuem o objetivo de dar a conhecer a um número maior de pessoas, dentro e fora da Academia, as experimentações literárias digitais produzidas em nosso país e seus autores, muitos ainda pouco conhecidos. Desse modo, as entrevistas tentam focar nos motivos e na trajetória que levaram seus autores à experimentação digital, bem como nos aspectos que envolvem a criação e a recepção de suas obras. Qualquer dúvida ou sugestão, entrar em contato através dos e-mails: literaturadigitalbrasileira@gmail.com ou mairaborgeswiese@gmail.com

Diniz Gonçalves Júnior (Diniz Antônio Gonçalves Bala Júnior, São Paulo/SP, 1971) é poeta, autor de Decalques e Concha Acústica.

Você tem dois livros de poemas publicados, o Decalques (2008) e o Concha Acústica (2012), além de poemas publicados em revistas e blogs (como na Zunái, Mallarmagens, etc), no seu blog Desmemórias, e vários poemas escritos sob o heterônimo Rabuja Rubirosa. Mas, além disso também se aventurou na poesia digital. Como você caracterizaria sua poesia? Quais são suas principais influências?

${ }^{1}$ Possui gradução em Letras pela Universidade Federal da Paraíba, com habilitação em Línguas e Literaturas de Língua Portuguesa e Inglesa, e mestrado em Estudos Literários e Culturais pela Faculdade de Letras da Universidade de Coimbra. Atualmente, é doutoranda bolsista (20152019) do programa de "Doutorado Pleno no Exterior", da CAPES, no Doutoramento "Estudos Avançados em Materialidades da Literatura", da mesma Faculdade portuguesa. Tem

como interesse principal estudos relacionados às literatura e poesia experimentais, e literatura e poesia eletrônicas e digitais dos séculos XX

e XXI. 

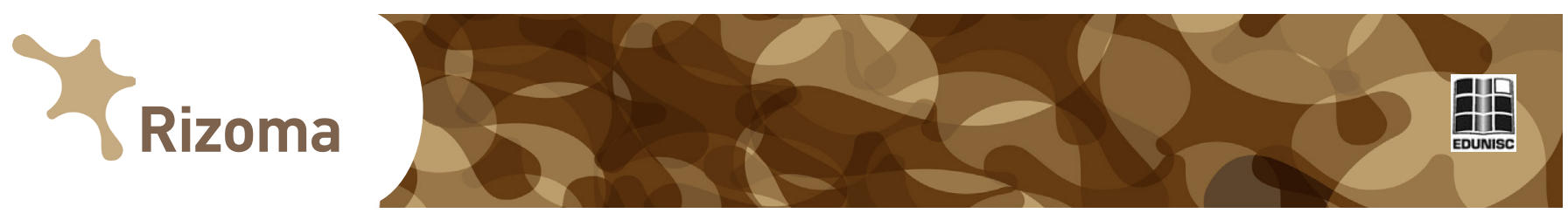

Falar de influências é sempre uma grande colcha de retalhos, mas basicamente cito os poetas do modernismo (Drummond, João Cabral, Bandeira, Murilo Mendes, Ribeiro Couto, etc) e a MPB. O contato com o trabalho dos concretistas nas aulas do Omar Khouri (Faculdade de Comunicação e Marketing - FAAP, UNESP) foi fundamental, principalmente no início da minha trajetória, de algum modo tardia porque comecei a escrever poesia aos 30 anos. Caetano e o Clube das Esquina não podem faltar, o primeiro mais cerebral e o segundo, coração. A melancolia do Guilherme Arantes e as referências urbanas. Sempre difícil definir o próprio trabalho artístico, percebo que houve uma guinada do hermetismo para um caminho mais simples e calcado no cotidiano. Meus poemas digitais devo à parceria com o artista multimeios Fábio Fon. Apresentado pelo Omar Khouri, tornou-se um amigo. Ele conseguiu traduzir minhas inquietações para o novo meio.

2. Como surgiu a participação na revista "Sígnica - Um balaio da era pós-verso (apesar do verso) (2000)"? Você contou com alguma parceria para a criação dos poemas Verticidade e Lúmen? Poderia explicar o processo de criação dessas obras?

A Sígnica foi criada pelo Fábio Fon, o Professor Pardal dos multimeios. Fiquei muito grato pelo convite e resolvi fazer dois poemas bem urbanos. "Verticidade" é a tentativa de captar algum lirismo da cidade. O texto desce como um letreiro brutalista. "Lúmen" apresenta o enigma das palavras-valise desveladas.

3. No poema Lúmen, publicado na revista Sígnica, o leitor assume o papel de iluminar as palavras do poema, para que assim possam ser vistas. Poderia comentar a escolha, nesse poema, dessa função interativa de iluminar o texto?

Uma lanterna no buraco da fechadura buscando significados: o leitor vai tateando as palavras estranhas (diluvidades, miriadoscópica).

4. O poema "Santos", publicado na revista Artéria (2008), foi concebido para a Web por Fábio Oliveira Nunes. Entretanto, ele está publicado no seu livro de poemas Decalques, de 2008. Trata-se, dessa forma, de uma releitura digital do poema? Qual foi sua participação nesta releitura?

A epígrafe do Eugen Fink sobre as ruínas da memória. Penso que a lembrança reúne os cacos em camadas, vivências verídicas ou falseadas. Eu pedi ao Fábio Fon uma tradução retrô, entreguei-lhe a foto do edífício verde-mar, projetado pelo Artacho Jurado, que havia fotografado com a máquina Zenith. Ele foi muito feliz ao construir o labirinto geométrico com as telinhas $\mathrm{p} \& \mathrm{~b}$.

\footnotetext{
5. Poderia escrever um breve diálogo com Rabuja Rubirosa no seu Autômato Poético?

Com o Rabuja, cavo mais fundo a nostalgia, tempos do bisavô até. O acesso imediato aos arquivos de todas as épocas que a internet propicia.
} 


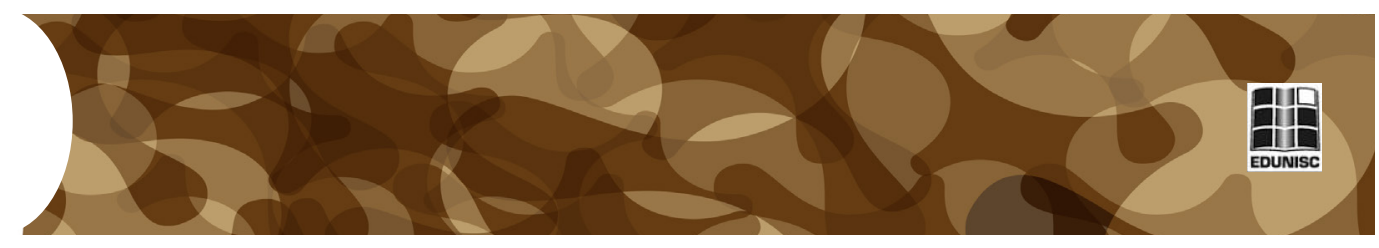

Batuta: COM QUE DANDI

Rabuja: samba canção ou ceroula?

Batuta: VALS

Rabuja: quentão ou vinho quente?

Batuta: QUENTÃO

Rabuja: estou geladinho

Batuta: KKK

Rabuja: vamos ao ponto chic?

Batuta: NÃO

Rabuja: caiu o monóculo

Batuta: NÃO

Rabuja: caiu o monóculo

Batuta: NÃO

Rabuja: quentão ou vinho quente?

Batuta: NADA OBRIGADO

Rabuja: por favor, diga agora

Batuta: POR

Rabuja: vamos ao ponto chic?

Batuta: PARA

Rabuja: casa de ferreiro, espeto de pau

6. Mantém interesse pela literatura/poesia digital? Se sim, quais autores, no Brasil e no mundo, mais lhe chamam a atenção?

Não acompanho tanto. Alguns trabalhos considero interessantes; outros me parecem videogames sem joystick. Cito Fábio Fon, trabalhos antigos do Augusto de Campos, Agnus Valente e Nardo Germano, Carlos Corpa.

\section{Alguns trabalhos digitais de Diniz Gonçalves Júnior:}

«Verticidade» (2002): http://www.nomuque.net/signica/verticidade1.html «Lúmen» (2002): http://www.nomuque.net/signica/lumen1.html «Santos» (2002/2008): http://www.nomuque.net/arteria8/home.html «Narciso sol de mim mesmo» (publicado na Revista digital-objeto "Nóisgrande" - 2006): https://www.youtube.com/watch?v=yrCRJvmMEVA

«Rabuja Rubirosa - Autômatos Poéticos» (2016): http://automatospoeticos. net/auto6/gui/plain/ Para saber mais acerca desse projeto: https://www.you-

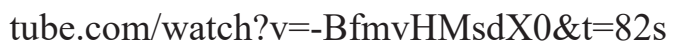

